\title{
REVIEW
}

\section{A Study on the Dilemma of Contemporary Teachers' Moral Life}

\section{Zhaojing Li*}

Nanjing Xiaozhuang University, Nanjing, Jiangsu, 211171, China

\begin{tabular}{l}
\hline ARTICLE INFO \\
\hline Article history \\
Received: 15 October 2019 \\
Revised: 22 October 2019 \\
Accepted: 9 April 2020 \\
Published Online: 16 April 2020 \\
\hline
\end{tabular}

\section{ABSTRACT}

The essence of teachers is to live a moral life with students and create a possible moral life together. At present, the alienation of teachers' moral life has reached an amazing degree. Based on this, at the conceptual level, rediscover the emotional dimension of teachers' moral life in a humanistic way and turn to the inner power of teachers' emotional life. At the practical level, it emphasizes the cultivation of emotional quality of moral life.

Keywords:

Teachers

Moral

Emotional literacy

\section{Introduction} The teacher is a person with moral influence who constructs moral life together with learners. However, in the face of frequent media reports of teachers' moral "anomie", student-teacher relationship crisis, "attack on teachers" and other vicious incidents. The emotional dimension of teacher as "human" is seriously covered. In the professional life of teachers, those teachers who create a high-quality moral life are interpreting the independent growth of teachers in the moral life.

\section{The Dilemma of Contemporary Teachers' Moral Life}

\subsection{Teachers Are Losing Their Emotional Autono- my}

Teachers' morality is understood as a series of professional rules and norms in modern society, and the individual behavior of teachers is strictly constrained and guided by reality. Teachers have seriously lost their autonomy and creativity in moral norms. Teachers are oppressed by various kinds of punishment-oriented

\footnotetext{
*Corresponding Author:

Zhaojing Li;

Nanjing Xiaozhuang University;

3601 Hongjing Avenue, Jiangning District, Nanjing City, Jiangsu Province, China, 211171;

E-mail:Kitten_baby@126.com

Fund Project:

1.This article is the phased research result of the Project on Ideological and Political Work in Philosophical and Social Sciences Research in Colleges and Universities in Jiangsu Province in 2019 Research on The role of the Party branch in the construction of young teachers' morality and style (Project NO 2019SJB120);

2.This article is also the phased research result of Special Topic of Ideological and Political Education in Higher Education Institutions of Social Sciences Applied Research in Jiangsu Province in 2019 Study on the Role of Party Branch in the Construction of Teachers' Morality of Young Teachers in Colleges and Universities in the New Era (19SZC-070).
} 
management related to their own interests. Over time, in addition to economic income, the work of teachers is no longer closely related to personal life significance and value pursuit.

\subsection{Teachers Are Overburdened by "Moral Ab- duction"}

Teachers are entrusted with the responsibility of inheriting virtue and educating the people, Zeng Shen said: When a ruler' s personal conduct is correct,his government is effective without giving orders. If his personal conduct is not correct,even he may give orders, but they will not be followed. ${ }^{[1]}$ Therefore, teachers are not only required to be moral self-discipliners, but also to be respected gentlemen. In fact, compared with ordinary people, teachers do not have moral priority. Under the guidance of public opinion and traditional teacher ethics, outsiders usually think that teachers should be moral people, moral role models and perfect moralists. Teachers give up the self-experience of moral life and the opportunity of self-evaluation and self-creation. Teachers even bear double moral pressure, long - term repression eventually led to the teacher's immoral life dilemma.

\subsection{Teacher's "Moral Indifference" Leads to Seri- ous Crisis in Teacher-Student Relationship}

At present, teachers' moral life is immersed in the increasingly exhausted plight: the blind pursuit of utilitarian pleasure trumps or even replaces the value judgment of virtue. Education and teaching activities become a kind of technical activities, which not only makes the moral life of teachers lose its true face, but also makes the value and essence of teachers as "people" covered. In order to realize the most effective knowledge transfer, educational and teaching activities are reduced to a kind of technical activities, which simply pursue functions and efficiency. In the end, educational and teaching activities become what Sato Manabu calls "teachers who are skilled in technology". Its characteristic is "the technology that aims at education and management is scientific, rationalize, flaunting the effective education that implements effective technology". "To determine the educational objectives, effectively control the educational process, objectively measure the educational effect, and improve the educational productivity." ${ }^{[2]}$ Under the heavy blow of entrance education and exam-oriented education, the output of teachers as "skilled technicians" has been directly presented as an evaluation system based on examination results, score-based work performance and promotion of students' academic achieve- ments. "The negative state of teachers' psychology and the phenomenon of inaction expressed by their behavior in the process of engaging in the profession of teachers" namely "moral indifference". ${ }^{[3]}$ Ignoring the emotional connection and spiritual communication between teachers and students will bring about great estrangement, resulting in serious crisis between teachers and students, and even more malignant and injurious incidents, paying a painful cost of life.

\section{Rediscovering Moral Life}

The reality of the society and the development of The Times require that everyone living in it should be responsible for his life and redefine his moral life in a humanistic way.

\subsection{The Cognition of Moral Life Begins to Search for the Interior of "Human"}

The definition of moral life is a process named constantly with the development of the times. Previous research on moral life is the expression of static value orientation, that is, moral life is one thing, and how to live moral life is another matter. This kind of speculation and inquiry prevents those people who are eager for the moral life from wandering outside the real-life experience. In recent years, the expression of moral life began to be more and more "grounded". For example, "moral life is the social value field in which people choose their behavior and evaluate their value in daily life". ${ }^{[4]}$ This expression means that life dominated by everyday morality is moral life. Furthermore, based on the deep subjective will of ethical researchers, moral life is interpreted as "a life with moral implications and capable of evaluating good and evil ". ${ }^{[5]}$ "Having moral implication" implies more subjective will of people in the main body of moral life than paying attention to moral content. "Anyone who can evaluate good and evil ${ }^{[6]}$ is the value judgment behavior of people's subjective initiative in life.

\subsection{Social Reality Requires A Re-Examination of Moral Life in A Humanistic Way}

Moral life is deeply stuck in an unprecedented state of stagnation. Each of us lives in a changeable, complex and contradictory world. Although economic growth and wealth pursuit have brought us irresistible positive effects, human beings have never been so busy pursuing materialization as to conceal what human beings should have. The abundance of the spiritual world and all kinds of speculation in utilitarianism have abandoned the settling of moral life. When we are confronted with all kinds of new problems 
in social transformation, the humanistic approach based on the overall situation will be the fundamental way out to solve them. Moral life cannot be separated from people's conscious discovery and self-creation. People are always the masters, controllers and creators of moral life. People's autonomous status in moral life determines the ownership and purpose of moral life. Therefore, moral life can be interpreted humanistically: moral life is the perceptual experience of life harmony in real life. It is based on good emotions and needs rational norms. It is often closely related to high-quality emotional life experience. It constantly pursues the meaning of life in the relationship and the conscious and self-conscious life of human beings. Moral life is both an end and a means. It is not only a means to a better life, but also a possibility to create a better life.

\section{The Turning of Contemporary Teachers' Moral Life}

\subsection{Turn to a Humanistic Approach Based on the Overall Situation and Pay Attention to Their Emotional Quality of Life}

Nowadays, the world is undergoing tremendous changes. In the face of common crises and uncertainties, people's morality is constantly under pressure. Therefore, "how to learn to coexist with others, how to maintain a moral life with more others, how to create a moral life in the interpersonal relationship with oneself" will become a realistic problem that every person based on the era of globalization must urgently reflect on and solve. "Education can help us accomplish a more arduous task - changing our way of thinking and world outlook. People need more opportunities to live meaningful lives and enjoy equal dignity, and education is essential for capacity-building to expand such opportunities." ${ }^{[7]}$ This is not only the requirement of the times, but also the requirement of education based on the overall situation. It is also the requirement of changing teachers' moral life and social ecology in a humanistic way.

\subsection{Attention to Supporting Emotional System Turning to Moral Life}

Paying attention to human emotional development is a fundamental and original problem in education,only emotion truly belongs to the individual. In this sense, the essence of human beings is the quality and expression of their emotions. A person's recognition, adherence to a certain value and even personality formation needs to be based on certain cognitive conditions, but it is essentially a process of emotional change and development, including the improvement and growth of internal emotional quality and external emotional ability. ${ }^{[8]}$ Without emotion, all education is impossible to talk about. Jaspers said: "Education cannot be without piety, otherwise it is at most an attitude of persuasion, and piety to the ultimate value and absolute truth is the essence of all education. Without absolute enthusiasm, people can't live, or they can't live like a person, and everything becomes meaningless." ${ }^{[9]}$ Therefore, it is necessary to return to the original experience of individual teachers in teachers' moral life, that is, to pay attention to the emotional dimension of teachers' moral life.

\subsection{Turning to Emotion— the Return of Life}

Current education obscures the most distinct attribute of human being as the relationship of life - the connection of emotions. The most precious "teacher's love" in teacher's life has disappeared. Living in a disciplined educational atmosphere for a long time, the attitude of teachers' life is atrophic and lifeless, and the most important emotion of life is obscured. The important point of teachers' moral life is that they have experienced a rich and profound emotional process, embodied the meaning of life, and found a greater value of life. The emotional basis of teachers' moral life seems to be more difficult to detect, but it is also these emotional bases that extend the new emotional variant - high emotional quality, and support and create teachers' good moral life.

\section{The Way Out of Contemporary Teachers' Moral Life}

After the reflection and transformation of teachers' moral life, facing the current predicament of teachers' moral life, teachers' moral life always needs to be in their own real life, and the predicament of moral life must be consciously observed and solved independently. Firstly, teachers should have a frank attitude, actively understand life, awaken the conscious consciousness of emotion-life; secondly, stimulate the conscious of life, awaken the emotional consciousness of moral life; finally, explore the intrinsic conditions and paths of teachers' moral life. We should pay attention to the cultivation of emotional literacy in moral life, noble personality support and fine moral sentiment, high sense of social responsibility and devotion to career, constantly improve and develop our internal driving force, good interpersonal communication and communication skills, and build harmonious relations and love of emotional civilization.

\section{References}

[1] Yanying Zhang. Analects of Confucius[M]. Beijing: 
Zhonghua Bookstore, 2006, 109. (in Chinese)

[2] Sato Manabu. Courses and Teachers[M]. Translated by Zhong Qiquan. Beijing: Educational Science Press, 2003, 263(206). (in Chinese)

[4] Shugui Yu. Theory of Moral Life[J]. Morality and Civilization, 2006(4). (in Chinese)

[5] Xiaoming Yi, Lan Yi. The Development of Moral Concept[J]. Qilu Journal, 2013(5). (in Chinese)

[6] Zhaoming Gao. On Moral Life[M]. Nanjing: Hehai University Press, 1993, 10. (in Chinese)
[7] United Nations Educational, Scientific and Cultural Organization. Reflective Education: Transforming to the Concept of "Global Common Interest"[R] 2015:32-33. (in Chinese)

[8] Xiaoman Zhu. Education Concerned about Spiritual Growth[M]. Beijing: Beijing Normal University Press, 2013, 231(26):257. (in Chinese)

[9] Jaspers. What is education[M]. Translated by Zou Jin. Shanghai: Life, Reading, Xinzhi Triple Bookstore, 1991, 44. (in Chinese) 